\title{
The Importance of Indoor Foliage Plants and Human Emotions to Indoor Foliage Plants
}

\author{
Hye Sook Jang, Gyung Mee Gim, Sun-Jin Jeong*, and Jae Soon Kim \\ National Institute of Horticultural \& Herbal Science, RDA, Wanju-gun 55365, South Korea
}

\begin{abstract}
This study was conducted to find out the sensibility reaction and importance with the visual element of indoor foliage plants in the survey of 216 participants. The eight kinds of leaf display plants were purchased and presented on white pot. The eight kinds of plant were included in ' 50 varieties of indoor foliage plants' announced by NASA and also easy to manage. The correlation between sensibility reaction, importance, loyalty to foliage plants and the expectation of therapeutic effect was investigated and analyzed by preference and Semantic Differential Scaling. Among importance factors of indoor foliage plant, the environmental, esthetic and emotional relaxation were high and the environmental and emotional relaxation were treated as important factors to age 40s or over especially. The result on the correlation between the expectation of therapeutic effect and, importance and loyalty of indoor foliage plant showed that the 'emotional relaxation' and 'increasing natural healing power of body' were correlated highest. In addition, significant correlation was shown statistically in five questions of expectation of therapeutic effect and loyalty. Especially, high correlation was shown in expectation of psychological stability effect of indoor foliage plant and working in an office where the indoor landscaping is created well. Significant differences were shown statistically with the emotional reactions between eight plants and "Comfortable", "Pleasant", "Calm", "Bright", and "Sharp" were representative emotional reactions to plants. Anthurium andraeanum cv. was the most preferred out of eight plants and Spathiphyllum spp.> Ficus benjamina $>$ Dypsis lutescens $>$ Dracaena marginata $>$ Rhapis excelsa > Hedera helix > Aglaonema commutatum was the order after. The most preferred leaf color of foliage plants was green. Recently, the environmental factors such as micro dust, stress and depression has been magnified and the stress relief, emotional relaxation and psychological stability effects of indoor foliage plants support the usefulness of them.
\end{abstract}

Keywords: emotional key words, preference of plants, stress recovery

\section{Introduction}

Humans born into nature are attracted to natural elements (Wilson, 2001). The more chances people have to see leaves of plants in nature (Kaplan and Kaplan, 1989), that is, the more people are visually exposed to natural environments such as plants, the more positive meanings they can find from natural elements, and the more positive experiences such as mindfulness and immersion they can experience, which was reported to restore their attention restoration ability and to

This study was supported by the Post-Doctoral Course Program of the National Institute of Horticultural and Herbal Science under the Rural Development Administration (PJ011376042017).

Received: March 20, 2018, Revised: April 19, 2018, Accepted: April 20, 2018

First author: Hye Sook Jang, E-mail: jhs915@korea.kr, ORCID: 0000-0003-3011-8694

*Corresponding author: Sun-Jin Jeong, E-mail: sunjin75@korea.kr, ORCID: 0000-0001-6279-9733 
result in recovery and therapy effects in other areas (Lee, 2014). Seeing indoor plants in artificially created indoor spaces gives not only environmental effects, but also emotional effects such as psychological stability and stress relief (Kwak, 2004; Lee, 2006). In addition, people who have more chances to look at natural plant leaves in daily life can restore their directed attention and experience their positive effects on emotional stability (Lee, 2006; Lee, 2007a). Moreover, even when people watch videos in which many natural elements frequently appear, without directly looking at real plants, they were found to recover from stress more quickly than when they watch videos of urban environments without any scene with plants (Parsons et al., 1998). In order to realize positive psychological interventions through natural environments, it is highly recommended to increase the frequency of contacting natural environments by utilize those that people can easily access in daily life (Lee, 2014). In addition, activities using plants psychologically give a sense of satisfaction, increase the level of concentration, creativeness and interest in and understanding of plants, and thus give a positive impact to people (Kim, 2001). Horticultural plants reduce the level of stress and maintain emotional stability (Kaplan, 2001), and they are also effective for psychological therapy (Ulrich, 1984). Creating natural environments utilizing horticultural plants can contribute to reducing the level of fine dust in Korea, significantly higher than other major cities in advanced countries (Ministry of Environment, 2016).

The level of fine dust (PM10) including yellow dust in Seoul, Korea is 1.5 times higher than that in LA, the United States, and 2 times higher than Paris, France and London, the United Kingdom, as of 2014, resulting in continuous environmental pollution (Ministry of Environment, 2016). According to a recent study conducted by a research team of the Medical School of Seoul National University, the correlation between air pollution and suicide rate was examined by analyzing the data of 265,746 adults collected by the National Health Insurance Service from 2002 to 2013, fine dust was found to have the strongest correlation with suicide rate among various air pollutants including fine dust, nitrogen dioxide and sulfur dioxide ("Micro dust increases", 2018). Air pollutants that are inhaled through respiratory organs activate cytokine proteins that cause inflammatory reactions in the body, which in turn results in systematic inflammatory responses and oxidative stress. As these factors are likely to cause psychological problems and increase the risk of attempting suicide, air pollution causes physical diseases, and also have a negative impact on mental health ("Micro dust increases", 2018; "Micro dust could be", 2018). In particular, continuous air pollution accelerates the production of stress hormones and negatively affect the metabolism of serotonin, increasing the risk of attempting suicide (Shin, 2015). The suicide rate for Korean people (per 100,000 persons per year) was 25.6 in 2016, over 2 times higher than the average suicide rate (12.1 persons) in OECD in 2017, showing the highest suicide rate among the OECD countries (Ministry of Health \& Welfare, 2018).

As the importance of environment and psychological stability has been highlighted, people tend to spend most of their time in indoor spaces blocked from the outside, and thus areas such as improving the environment of indoor spaces and psychological and emotional stability have emerged as important research areas. Against this backdrop, this study aimed to analyze the correlation between people's awareness of indoor foliage plants and their psychological effects in modern society pursuing wellness, to improve the utilization of indoor foliage plants, and to confirm their usefulness in improving psychological effects such as stress relief and improved stability. By doing so, people's access to indoor foliage plants can be increased and information that is useful to promote mental health can be suggested in this study.

\section{Research Methods}

\section{Criteria for selecting indoor foliage plants for assessing emotional images and preference}

In order to assess subjects' emotional reactions to and preference for the visual elements of indoor foliage plants, eight 
plants that can be easily grown and of which leaves have ornamental values were selected from the list of the ' 50 plants that clean the air' announced by the National Aeronautics and Space Administration (NASA) of the United States (Song, $2015)$ (Fig. 1). The selected indoor foliage plants were purchased and planted in a white plastic pot $(\varnothing 25 \times \mathrm{H} 18 \pm 5 \mathrm{~cm})$ for a questionnaire survey. The growth conditions of the purchased plants were very good, and their plant height and volume are as shown in Table 1. As a part of research on air purification for the completely sealed environment of spacecrafts in space, NASA tested the air purifying effects of plants that were known to be effective to purify the air based on 4 criteria, including their capacity of reducing volatile chemicals, transpiration rate, convenience in growing and maintaining plants and adaptability to harmful insects.

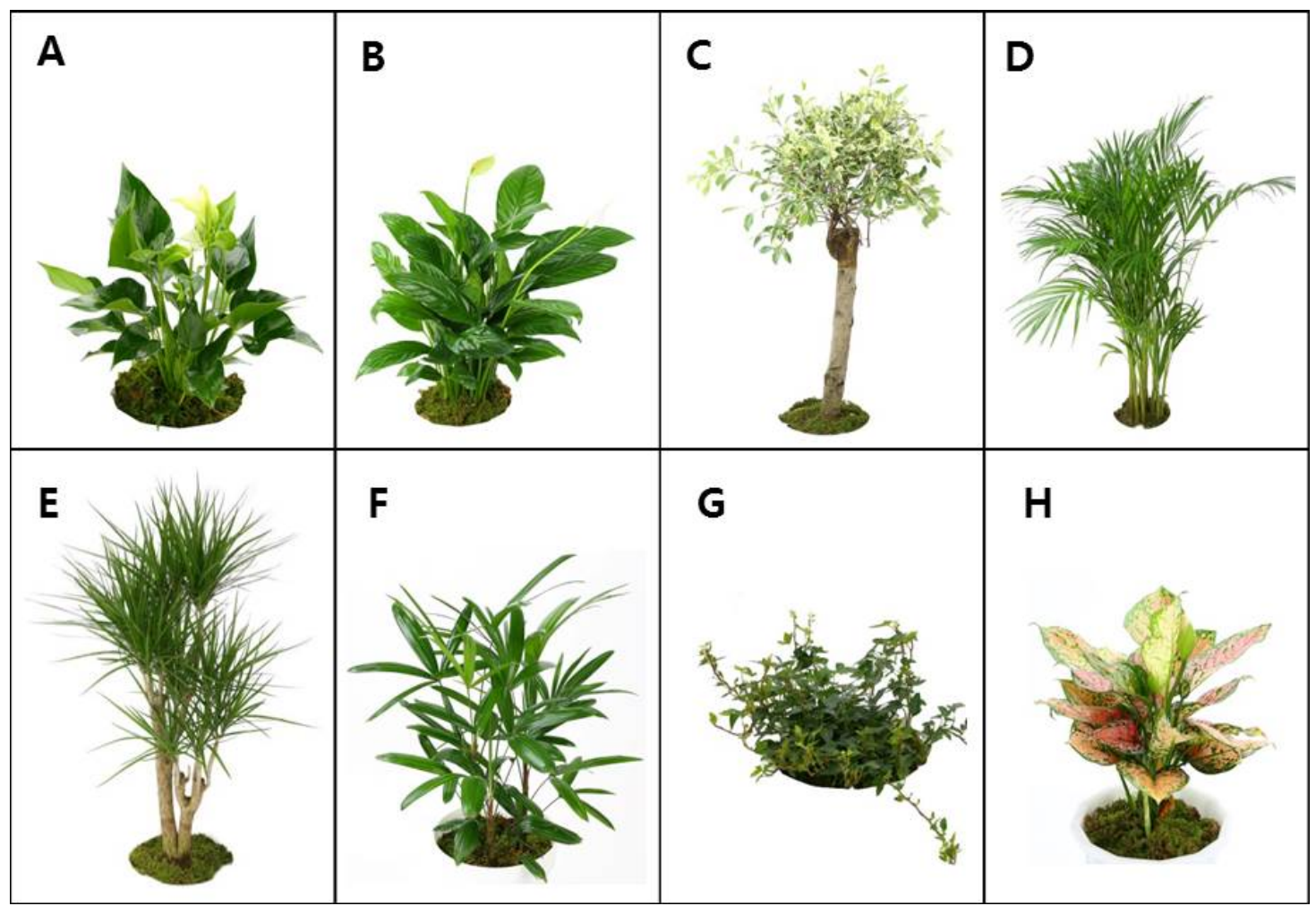

Figure 1. Eight Indoor foliage plants for the survey. $\mathrm{A}=$ Anthurium andraeanum $\mathrm{cv}$.; $\mathrm{B}=$ Spathiphyllum spp.; $\mathrm{C}=$ Ficus benjamina 'Variegata'; $\mathrm{D}=$ Dypsis lutescens; $\mathrm{E}=$ Dracaena marginata; $\mathrm{F}=$ Rhapis excelsa; $\mathrm{G}:=$ Hedera helix, $\mathrm{H}=$ Aglaonema commutatum 'Lady Valentine'.

Table 1. Plant height and width of indoor foliage plants for the survey

\begin{tabular}{cccc}
\hline Plant & Species & Plant height $(\mathrm{cm})$ & Width $(\mathrm{cm})$ \\
\hline A & Anthurium andraeanum cv. & $50 \pm 5$ & $40 \pm 5$ \\
B & Spathiphyllum spp. & $58 \pm 5$ & $40 \pm 5$ \\
C & Ficus benjamina 'Variegata' & $93 \pm 5$ & $45 \pm 5$ \\
D & Dypsis lutescens & $105 \pm 5$ & $90 \pm 5$ \\
E & Dracaena marginata & $105 \pm 5$ & $40 \pm 5$ \\
F & Rhapis excelsa & $60 \pm 5$ & $45 \pm 5$ \\
G & Hedera helix & $20 \pm 5$ & $30 \pm 5$ \\
H & Aglaonema commutatum 'Lady Valentine' & $28 \pm 5$ & $30 \pm 5$ \\
\hline
\end{tabular}




\section{General characteristics of respondents}

In order to examine general people's awareness of indoor foliage plants, 226 workers in and visitors to public buildings were surveyed through questionnaires after directly showing actual plants purchased from the market. A total of 216 answer sheets, excluding 10 insufficient answers, were analyzed (Fig. 1). Frequency analysis was performed on general characteristics, and the share of males and females was $33.3 \%$ and $66.7 \%$ respectively. The share of those in their $40 \mathrm{~s}$ was the highest (34.7\%), followed by those in their 20s (26.4\%), 50s (22.7\%), 30s (13.9\%), and 60s or older (2.3\%). In addition, in terms of academic background, those who graduated college (or in college) accounted for 40.7\%; those who graduated graduate school (or in graduate school), 35.2\%; those who graduated high school, 20.4\%; and others, 3.7\%. The questionnaire was composed of the following items: awareness of the importance of indoor foliage plants, and their frequency and differences between age groups; expectations on the therapeutic effects of indoor foliage plants (5 questions: Cronbach's $\alpha=0.758$ ) to analyze the correlation between the importance of and loyalty towards plants; and emotional reactions and preference for the 8 indoor foliage plants and preference for the colors of leaves. Subjects' expectations on the therapeutic effects of indoor foliage plants were assessed with 5 questions using Likert 4-point scale ( 1 point: extremely not, 4 points: extremely so) (Jang et al., 2015, 2017; Kim, 2012) to analyze the correlation between the importance of and loyalty towards plants. Loyalty is defined as the level of consumers' positive feelings towards products or services (Dick and Basu, 1994) that are measured based on consumers' intention of purchase and behaviors (Lee, 2003). The scale of consumers' loyalty developed by Gremler (1995) was revised according to the circumstances of indoor foliage plants (Jang et al., 2011, 2017). It was assessed with a total of 5 questions using Likert 5-point scale (Zeisel, 1981). The reliability of the 5-question measurement tool for loyalty used in this study was Cronbach's $\alpha=0.776$.

\section{Awareness of the importance of indoor foliage plants}

Subjects' awareness of the importance of indoor foliage plants was assessed based on relevant literature (Kwak, 2004), and measurement tools of which Cronbach's $\alpha$ is higher than 0.6-0.7 are recognized to be highly reliable (Lee, 2008). In this study, the six criteria (composed of 22 questions) for measuring the awareness of importance (Cronbach's $\alpha=0.882$ ) used by Jang et al. (2011) were used in this study, and subjects were instructed to answer each question using Likert 5 -point scale. The reliability level of the 6 criteria used in this study was Cronbach's $\alpha=0.666$. The six criteria were composed as follows: Factor 1, emotional relaxation such as feeling stable and relaxed through plants; Factor 2, closedness such as feeling confined due to excessively high green coverages or laid-out plants that block out light; Factor 3, aesthetic that create comfortable atmospheres; Factor 4, naturalness that creates natural spaces such as forests and gives a sense of seasons by laying out plants; Factor 5, differentiation through plants'unique natural scents and colors; and Factor 6, environmental effects such as pleasant spaces and cir conditioning (Jang et al., 2011).

\section{Measuring emotional words using Semantic Differential (SD) method}

The Semantic Differential (SD) method is widely used to quantify landscapes depending on subjective tastes and preference based on the correlation between emotional adjectives and emotional factors that are identified through factor analysis (Kim, 2012; Park, 2010; Jang et al., 2011). The emotions that respondents felt when they looked at the images of plants were measured using adjectives used in assessing landscapes (Im, 2009) and 14 pairs of emotional words associated with plants using the SD scale suggested by Osgood et al. (1957) (Jang, 2013; Jang et al., 2011, 2015; Kim, 2009; Lee, 2006). Actual plants were directly shown to respondents and 14 pairs of emotional words were suggested to them. Each of the suggested emotional adjectives was divided into 5 grades, and respondents were instructed to choose one grade that is 
the closest to their emotion that they felt when looking at the presented plant. The reliability level of the 14 pairs of emotional words was found to be very high (Cronbach's $\alpha=0.849$ ).

\section{Statistical analysis}

Statistical analysis in this study was carried out using IBM SPSS ver. 25.0. Cronbach's $\alpha$ was calculated to analyze the reliability of the assessment tool. The 14 pairs of emotional reactions surveyed using the SD method, the importance of 6 factors, and subjects' preference for indoor foliage plants and their leaf colors were analyzed using one-way ANOVA. Scheffé's multiple range test was performed as a post-hoc test. In addition, the correlation between questions on subjects' expectations on the therapeutic effects of indoor foliage plants, importance and loyalty was analyzed using paired correlation analysis, and frequency analysis was carried out on the general characteristics of subjects and the ratio of importance.

\section{Results and Discussion}

\section{Awareness of the importance of indoor foliage plants and differences between age groups}

Subjects' awareness of the importance of indoor foliage plants was surveyed (Table 2), and the share of those who answered that environmental factors are very important was the highest (48.1\%), followed by aesthetic (44.9\%), emotional relaxation (43.9\%), differentiation (27.0\%), naturalness (19.6\%), and closedness (4.7\%). In addition, the awareness was also analyzed by age group (Table 3), and only the factor of emotional relaxation, out of the 6 factors, showed statistically significant differences between age groups. Those in their 20 s and 30 s tended to value aesthetic

Table 2. Percent of awareness of importance of indoor foliage plant by six factors (unit: \%)

\begin{tabular}{|c|c|c|c|c|c|}
\hline Factor & Not important at all & Not important & Normal & Important & Very importan \\
\hline Emotional relaxation & 0.0 & 1.0 & 5.1 & 50.0 & 43.9 \\
\hline Closedness & 0.9 & 16.3 & 41.9 & 36.2 & 4.7 \\
\hline Aesthetic & 0.0 & 0.0 & 1.9 & 53.2 & 44.9 \\
\hline Naturalness & 0.0 & 2.3 & 22.0 & 56.1 & 19.6 \\
\hline Differentiation & 0.9 & 1.9 & 24.6 & 45.6 & 27.0 \\
\hline Environmental & 0.0 & 0.0 & 7.9 & 44.0 & 48.1 \\
\hline
\end{tabular}

Table 3. Age specific awareness of importance of indoor foliage plant by six factors on a 5-point scale

\begin{tabular}{lccccccc}
\hline \multicolumn{1}{c}{ Factor } & $20 \mathrm{~s}$ & $30 \mathrm{~s}$ & $40 \mathrm{~s}$ & $50 \mathrm{~s}$ & 60 or over & $\mathrm{F}$ & $p$ \\
\hline Emotional relaxation & $3.853 \pm 0.74 \mathrm{a}$ & $4.133 \pm 0.58 \mathrm{ab}$ & $4.152 \pm 0.59 \mathrm{ab}$ & $4.221 \pm 0.47 \mathrm{~b}$ & $4.000 \pm 0.66 \mathrm{ab}$ & 2.956 & $.021^{*}$ \\
Closedness & $3.147 \pm 0.65 \mathrm{a}$ & $2.983 \pm 0.71 \mathrm{a}$ & $2.950 \pm 0.92 \mathrm{a}$ & $2.776 \pm 0.73 \mathrm{a}$ & $2.700 \pm 0.69 \mathrm{a}$ & 1.635 & .167 \\
Aesthetic & $4.158 \pm 0.49 \mathrm{a}$ & $4.269 \pm 1.61 \mathrm{a}$ & $4.051 \pm 0.45 \mathrm{a}$ & $4.090 \pm 0.39 \mathrm{a}$ & $3.880 \pm 0.41 \mathrm{a}$ & 0.673 & .612 \\
Naturalness & $3.637 \pm 0.72 \mathrm{a}$ & $3.598 \pm 1.27 \mathrm{a}$ & $3.644 \pm 0.64 \mathrm{a}$ & $3.597 \pm 0.62 \mathrm{a}$ & $3.467 \pm 0.69 \mathrm{a}$ & 0.092 & .985 \\
Differentiation & $3.833 \pm 0.87 \mathrm{a}$ & $3.638 \pm 0.98 \mathrm{a}$ & $3.773 \pm 0.74 \mathrm{a}$ & $3.827 \pm 0.73 \mathrm{a}$ & $4.100 \pm 0.42 \mathrm{a}$ & 0.518 & .723 \\
Environmental & $3.971 \pm 0.61 \mathrm{a}$ & $4.222 \pm 0.53 \mathrm{a}$ & $4.209 \pm 0.51 \mathrm{a}$ & $4.088 \pm 0.45 \mathrm{a}$ & $4.000 \pm 0.58 \mathrm{a}$ & 2.029 & .091 \\
\hline
\end{tabular}

Note. Mean separation within columns by Scheffé's multiple range test, $5 \%$ level $(p<.05)$. Mean \pm standard deviation $(\mathrm{N}=216)$.

*Significant at $p<.05$ by one way ANOVA. 
effects the most, but there was no statistically significant difference between age groups. Those in their 40s and 50s valued environmental effects and emotional relaxation the most respectively. Those in their 60 s or older were found to value differentiation, environmental effects and emotional relaxation. These results showed differences between age groups in their awareness of the importance of indoor foliage plants and what they value when treating plants (Table 2). The high percentages of environmental effects, aesthetic effects and emotional relaxation indicate that people tend to pursue wellness for their happy and healthy life in the age of centenarians. In particular, the result that those in their 40s or older valued environmental effects and emotional relaxation is consistent with the results of earlier studies that people tend to prioritize psychological relaxation when laying out indoor plants (Kwak, 2004; Lee, 2010). In addition, in an earlier study that analyzed expectations on the functions of indoor landscapes by dividing them into psychological, perceptional and environmental functions (Yoo, 2013), the expectation on the psychological function was the highest, followed by the environmental function, showing statistically significant differences. In another study (Ulrich, 1979), it was found that simply looking at the landscape of plants reduced the level of stress. These results support the usefulness of indoor plants.

\section{Correlation between items for assessing expectations on the therapeutic effects of indoor foliage plants and their importance and loyalty}

The correlation between items for assessing subjects' expectations on the therapeutic effects of indoor foliage plants, and their importance was analyzed, and out of the six factors including emotional relaxation, closedness, aesthetic effects, naturalness, differentiation and environmental effects (Jang et al., 2011), closedness showed a negative correlation, and the rest five factors showed a positive correlation. In particular, the positive correlation between emotional relaxation and

Table 4. Correlation between items for accessing expectations on the therapeutic effects of indoor foliage plants and their importance and loyalty

\begin{tabular}{ccccccc}
\hline Variable & Factor & $\mathrm{A}^{\mathrm{z}}$ & $\mathrm{B}$ & $\mathrm{C}$ & $\mathrm{D}$ & $\mathrm{E}$ \\
\hline \multirow{4}{*}{ Importance } & Emotional relaxation & $.278^{* *}$ & $.297^{* *}$ & $.372^{* *}$ & $.361^{* *}$ & $.405^{* *}$ \\
& Closedness & -.042 & -.107 & $-.147^{*}$ & $-.301^{* *}$ & $-.177^{* *}$ \\
& Aesthetic & $.151^{*}$ & .070 & .060 & .105 & $.135^{*}$ \\
& Naturalness & .094 & .122 & .035 & .100 & $.153^{*}$ \\
& Differentiation & $.231^{* *}$ & $.150^{*}$ & .054 & .003 & .075 \\
Loyalty & Environmental & $.266^{* *}$ & $.169^{*}$ & $.321^{* *}$ & $.309^{* *}$ & $.206^{* *}$ \\
& L1 & $.284^{* *}$ & $.281^{* *}$ & $.331^{* *}$ & $.263^{* *}$ & $.234^{* *}$ \\
& L2 & $.268^{* *}$ & $.343^{* *}$ & $.342^{* *}$ & $.308^{* *}$ & $.307^{* *}$ \\
& L3 & $.314^{* *}$ & $.309^{* *}$ & $.322^{* *}$ & $.360^{* *}$ & $.353^{* *}$ \\
& L4 & $.254^{* *}$ & $.273^{* *}$ & $.375^{* *}$ & $.326^{* *}$ & $.288^{* *}$ \\
\hline
\end{tabular}

Note. Likert 5-point scale was used for importance, where 1=not important at all; 5=very important, for loyalty, $1=$ extremely not; $5=$ extremely so. Likert 4-point scale was used for expectation of therapeutic effects, where 1=extremely not; 4=extremely so.

${ }^{\mathrm{z}} \mathrm{A}=$ =Indoor foliage plants increase air purifying effects; $\mathrm{B}=$ Indoor foliage plant can cure an atopic dermatitis; $\mathrm{C}=$ =Indoor foliage plants can improve the work efficiency of workers; $\mathrm{D}=$ Indoor foliage plants improve psychological stability; $\mathrm{E}=$ Indoor foliage plants increase the natural healing power of body.

${ }^{\mathrm{y}} \mathrm{L} 1=\mathrm{Be}$ able to talk positively to other people regarding growing indoor foliage plants; L2=Intend to purchase more indoor foliage plants; L3=Strongly recommend to purchase indoor foliage plants to relatives or friends; L4=It was the best decision purchasing the indoor foliage plants; L5=I would like to move to an office that has a well-created indoor landscape.

${ }^{*}{ }^{* *}$ Significant at $p<.05, .01$, respectively $(\mathrm{N}=216)$. 
the question "indoor foliage plants increase the natural healing power of the body" was the highest (over 0.4). In addition, questions including "indoor foliage plants improve the work efficiency of workers" and "indoor foliage plants improve psychological stability" showed a positive correlation (over 0.3 ) with the factors including emotional relaxation and environmental effects (Table 4).

In addition, the correlation between questions about subjects's expectations on the therapeutic effects of indoor foliage plants and loyalty was analyzed, and all the five questions showed a statistically significant positive correlation. In particular, questions including "indoor foliage plants improve psychological stability" and Question 5 on loyalty "I want to move to an office that has a well-created indoor landscape" showed the highest positive correlation (.393) (Table 4). The results of an earlier study that users of large general hospitals preferred plants the most to other natural elements, and that direct access to natural elements including plants can be an effective therapeutic factor for users (Choi, 2012) support the highly positive correlation between plants and environment, therapy and emotional health that was found in this study. In addition, an earlier study on the correlation between green coverage and emotional health also reported that chances to contact natural environments improve emotional health (Lee, 2007a, b).

\section{Emotional reactions to 8 indoor foliage plants}

Emotional reactions to the images of 8 indoor foliage plants were surveyed using Likert 5-point scale (Table 5), and there were statistically significant differences between respondents' emotional reactions to 8 indoor foliage plants $(p<$

Table 5. The result of emotional reactions to indoor foliage plants by 5-point Semantic Differential scale

\begin{tabular}{|c|c|c|c|c|c|c|c|c|c|c|}
\hline \multirow[b]{2}{*}{ Variance } & \multicolumn{8}{|c|}{ Plant } & \multirow[b]{2}{*}{$\mathrm{F}$} & \multirow[b]{2}{*}{$p$} \\
\hline & $\begin{array}{c}\text { Anthurium } \\
\text { andraeanum } \\
\text { cv. }\end{array}$ & $\begin{array}{l}\text { Spathiphyllum } \\
\text { spp. }\end{array}$ & $\begin{array}{c}\text { Ficus } \\
\text { benjamina } \\
\text { 'Variegata' }\end{array}$ & $\begin{array}{l}\text { Dypsis } \\
\text { lutescens }\end{array}$ & $\begin{array}{l}\text { Dracaena } \\
\text { marginata }\end{array}$ & $\begin{array}{l}\text { Rhapis } \\
\text { excelsa }\end{array}$ & $\begin{array}{l}\text { Hedera } \\
\text { helix }\end{array}$ & $\begin{array}{c}\text { Aglaonema } \\
\text { commutatum } \\
\text { 'Lady Valentine' }\end{array}$ & & \\
\hline $\mathrm{B} 1^{\mathrm{z}}$ & $4.13 \pm 0.8 b c$ & $3.63 \pm 1.0 \mathrm{~b}$ & $4.60 \pm 0.7 \mathrm{c}$ & $4.25 \pm 0.8 b c$ & $2.70 \pm 1.2 \mathrm{a}$ & $2.71 \pm 1.1 \mathrm{a}$ & $2.45 \pm 1.0 \mathrm{a}$ & $3.73 \pm 0.9 \mathrm{~b}$ & 39.111 & .000 \\
\hline B2 & $4.18 \pm 0.9 \mathrm{c}$ & $3.59 \pm 1.0 \mathrm{bc}$ & $4.22 \pm 0.9 \mathrm{c}$ & $3.61 \pm 1.2 \mathrm{bc}$ & $2.53 \pm 1.1 \mathrm{a}$ & $3.00 \pm 1.0 \mathrm{ab}$ & $2.73 \pm 1.0 \mathrm{a}$ & $3.18 \pm 1.0 \mathrm{ab}$ & 21.876 & .000 \\
\hline B3 & $3.61 \pm 1.0 \mathrm{bcd}$ & $2.88 \pm 1.0 \mathrm{ab}$ & $3.82 \pm 1.2 \mathrm{~d}$ & $3.67 \pm 1.1 \mathrm{~cd}$ & $2.82 \pm 1.0 \mathrm{a}$ & $3.00 \pm 1.1 \mathrm{abc}$ & $3.04 \pm 1.1 \mathrm{abc}$ & $2.86 \pm 0.9 \mathrm{a}$ & 8.819 & .000 \\
\hline B4 & $3.20 \pm 0.8 \mathrm{~d}$ & $3.41 \pm 1.1 \mathrm{bcd}$ & $4.11 \pm 1.0 \mathrm{~d}$ & $3.40 \pm 1.1 \mathrm{bcd}$ & $3.96 \pm 1.1 \mathrm{a}$ & $3.11 \pm 1.1 \mathrm{abc}$ & $2.90 \pm 0.9 \mathrm{ab}$ & $4.07 \pm 0.9 \mathrm{~cd}$ & 16.365 & .000 \\
\hline B5 & $4.32 \pm 0.9 \mathrm{c}$ & $3.91 \pm 0.9 \mathrm{bc}$ & $4.00 \pm 1.2 \mathrm{ab}$ & $3.54 \pm 1.2 \mathrm{abc}$ & $3.65 \pm 1.1 \mathrm{a}$ & $3.25 \pm 1.1 \mathrm{abc}$ & $2.90 \pm 1.2 \mathrm{ab}$ & $3.18 \pm 1.2 \mathrm{a}$ & 10.120 & .000 \\
\hline B6 & $3.23 \pm 0.8 b$ & $2.80 \pm 1.0 \mathrm{ab}$ & $3.11 \pm 1.1 b$ & $3.13 \pm 1.0 \mathrm{~b}$ & $2.35 \pm 1.1 \mathrm{a}$ & $2.87 \pm 1.0 \mathrm{ab}$ & $2.60 \pm 0.9 \mathrm{ab}$ & $2.65 \pm 1.2 \mathrm{ab}$ & 4.833 & .000 \\
\hline B7 & $4.32 \pm 0.8 \mathrm{e}$ & $3.91 \pm 0.9 \mathrm{cde}$ & $4.00 \pm 1.1 \mathrm{de}$ & $3.54 \pm 1.0 \mathrm{abcd}$ & $3.65 \pm 1.0 \mathrm{bcde}$ & $3.25 \pm 0.9 \mathrm{abc}$ & $2.90 \pm 1.1 \mathrm{a}$ & $3.18 \pm 1.1 \mathrm{ab}$ & 11.975 & .000 \\
\hline B8 & $3.20 \pm 1.0 \mathrm{a}$ & $3.41 \pm 1.1 \mathrm{ab}$ & $4.11 \pm 0.9 b$ & $3.40 \pm 0.9 \mathrm{ab}$ & $3.96 \pm 1.0 \mathrm{~b}$ & $3.11 \pm 1.1 \mathrm{a}$ & $2.90 \pm 1.0 \mathrm{a}$ & $4.07 \pm 1.0 \mathrm{~b}$ & 11.600 & .000 \\
\hline B9 & $3.82 \pm 1.1 \mathrm{a}$ & $4.13 \pm 0.8 \mathrm{a}$ & $3.60 \pm 1.2 \mathrm{a}$ & $3.71 \pm 1.0 \mathrm{a}$ & $4.07 \pm 0.7 \mathrm{a}$ & $3.87 \pm 0.7 \mathrm{a}$ & $3.45 \pm 1.1 \mathrm{a}$ & $3.79 \pm 0.8 \mathrm{a}$ & 3.047 & .004 \\
\hline B10 & $4.16 \pm 0.8 \mathrm{~d}$ & $4.09 \pm 0.8 \mathrm{~d}$ & $3.96 \pm 1.0 \mathrm{~cd}$ & $3.64 \pm 0.9 \mathrm{abcd}$ & $3.85 \pm 0.9 \mathrm{bcd}$ & $3.38 \pm 1.0 \mathrm{abc}$ & $3.04 \pm 0.8 \mathrm{a}$ & $3.29 \pm 1.2 \mathrm{ab}$ & 10.496 & .000 \\
\hline B11 & $4.25 \pm 0.7 \mathrm{~d}$ & $4.04 \pm 0.8 \mathrm{~cd}$ & $4.04 \pm 1.0 \mathrm{~cd}$ & $3.60 \pm 1.1 \mathrm{bcd}$ & $3.56 \pm 1.1 \mathrm{bcd}$ & $3.44 \pm 1.0 \mathrm{abc}$ & $3.22 \pm 1.0 \mathrm{ab}$ & $2.75 \pm 1.2 \mathrm{a}$ & 13.560 & .000 \\
\hline B12 & $4.18 \pm 0.7 \mathrm{~d}$ & $3.96 \pm 0.7 \mathrm{~cd}$ & $3.40 \pm 1.1 \mathrm{bc}$ & $3.09 \pm 1.1 \mathrm{~b}$ & $3.02 \pm 1.1 \mathrm{ab}$ & $3.58 \pm 1.0 \mathrm{bcd}$ & $2.96 \pm 1.2 \mathrm{ab}$ & $2.32 \pm 1.1 \mathrm{a}$ & 18.914 & .000 \\
\hline B13 & $4.36 \pm 0.6 \mathrm{e}$ & $4.09 \pm 0.7 \mathrm{de}$ & $3.69 \pm 1.0 \mathrm{cde}$ & $3.53 \pm 1.0 \mathrm{bcd}$ & $2.91 \pm 1.1 \mathrm{ab}$ & $3.53 \pm 1.1 \mathrm{bcd}$ & $3.00 \pm 1.1 \mathrm{abc}$ & $2.68 \pm 1.0 \mathrm{a}$ & 20.385 & .000 \\
\hline B14 & $3.14 \pm 1.2 \mathrm{abc}$ & $3.38 \pm 1.1 \mathrm{abcd}$ & $3.89 \pm 1.1 \mathrm{~cd}$ & $3.15 \pm 1.2 \mathrm{abc}$ & $3.44 \pm 1.0 \mathrm{bcd}$ & $3.04 \pm 1.1 \mathrm{ab}$ & $2.65 \pm 1.0 \mathrm{a}$ & $3.96 \pm 1.0 \mathrm{~d}$ & 8.714 & .000 \\
\hline
\end{tabular}

Note. Mean separation within columns by Scheffé's multiple range test, $5 \%$ level $(\mathrm{N}=216)$.

${ }^{\mathrm{z}} \mathrm{B} 1=$ Dark-bright; B2=Hard-soft; B3=Heavy-light; B4=Cool-warm; B5=Complicated-simple; B6=Strong-pale; B7=Cheap-luxurious; B8=Commonplaceunique; B9=Restrained-sharp; B10=Provincial-sophisticated; B11=Unpleasant-pleasant; B12=Vibrant-calm; B13=Uneasy-comfortable; B14=Modestfancy.

Significant at $p<.01, .001$ by one way ANOVA. Mean \pm standard deviation $(\mathrm{N}=216)$. 
Table 6. Representative emotional reactions to eight indoor foliage plants

\begin{tabular}{|c|c|c|c|c|}
\hline \multirow{2}{*}{ Indoor foliage plant } & \multicolumn{4}{|c|}{ Emotional reaction (ranked in order) } \\
\hline & 1 & 2 & 3 & 4 \\
\hline Anthurium andraeanum $\mathrm{cv}$. & comfortable & simple & luxurious & pleasant \\
\hline Spathiphyllum spp. & sharp & comfortable & sophisticated & pleasant \\
\hline Ficus benjamina 'Variegata' & bright & soft & warm & unique \\
\hline Dypsis lutescens & bright & sharp & light & sophisticated \\
\hline Dracaena marginata & sharp & warm & unique & sophisticated \\
\hline Rhapis excelsa & sharp & calm & comfortable & pleasant \\
\hline Hedera helix & sharp & pleasant & light & sophisticated \\
\hline Aglaonema commutatum 'Lady Valentine' & warm & unique & fancy & sharp \\
\hline
\end{tabular}

.05). Key emotional reactions to Anthurium andraeanum cv. include "comfortable", "simple", "luxurious", and "likable", and those to Spathiphyllum spp. include "sharp", "calm", "comfortable", and "sophisticated". Key emotional reactions to Dypsis lutescens include "bright", "sharp", and "light", and those to Hedera helix include "sharp", and "likable". Those to Ficus benjamina 'Variegata', Dracaena marginata and Aglaonema commutatum 'Lady Valentine' include "bright", "warm", and "unique". In particular, similar to the results of preference survey on 8 indoor foliage plants, a large number of respondents chose "comfortable" and "likable" for Anthurium andraeanum cv. and Spathiphyllum spp. (Tables 5, 6). These results were similar to those of a study on the modularized interior landscape designs that the common adjectives for Anthurium andraeanum cv. were "modest" and "stable", and those for Spathiphyllum spp., "modest", "calm", and "comfortable" (Yoo, 2007), which indicates that respondents felt calm and comfortable.

\section{Preference for 8 indoor foliage plants}

Subjects' preference for 8 indoor foliage plants was surveyed (Table 7), and there were statistically significant

Table 7. Preference for indoor foliage plants on 5-point scale

\begin{tabular}{|c|c|c|c|c|c|c|c|c|c|}
\hline & \multirow{2}{*}{ Plant } & \multirow{2}{*}{$\mathrm{n}$} & \multirow{2}{*}{ M } & \multirow{2}{*}{$\mathrm{SD}$} & \multicolumn{5}{|c|}{ Scheffe's test $\alpha=0.05$} \\
\hline & & & & & 1 & 2 & 3 & 4 & 5 \\
\hline \multirow{10}{*}{ Preference } & Aglaonema commutatum & 56 & 2.57 & 1.01 & $\mathrm{a}^{\mathrm{z}}$ & & & & \\
\hline & Hedera helix & 51 & 2.98 & 0.84 & $\mathrm{a}$ & $\mathrm{b}$ & & & \\
\hline & Rhapis excelsa & 55 & 3.16 & 0.86 & a & $\mathrm{b}$ & $\mathrm{c}$ & & \\
\hline & Dracaena marginata & 55 & 3.25 & 0.97 & & $\mathrm{~b}$ & $\mathrm{c}$ & $d$ & \\
\hline & Dypsis lutescens & 55 & 3.29 & 1.07 & & $\mathrm{~b}$ & $\mathrm{c}$ & $\mathrm{d}$ & $\mathrm{e}$ \\
\hline & Ficus benjamina & 55 & 3.76 & 1.07 & & & $\mathrm{c}$ & d & $\mathrm{e}$ \\
\hline & Spathiphyllum spp. & 56 & 3.84 & 0.65 & & & & $\mathrm{~d}$ & $\mathrm{e}$ \\
\hline & Anthurium andraeanum cv. & 56 & 3.93 & 0.68 & & & & & $\mathrm{e}$ \\
\hline & F-value & & & & 14.831 & & & & \\
\hline & $p$-value & & & & $0.000^{* * *}$ & & & & \\
\hline
\end{tabular}

Note. Likert 5-point scale was used for preference, where 1=dislike very much; $5=$ like very much.

${ }^{\mathrm{z}}$ Mean separation within columns by Scheffé's multiple range test, $5 \%$ level $(\mathrm{n}=56)$.

${ }^{* * *}$ Significant at $p<.001$. 
differences between subject's preference for 8 indoor foliage plants $(\mathrm{F}=14.831, p=0.000)$. Their preference for Anthurium andraeanum cv. was the highest (3.93), followed by Spathiphyllum spp., Ficus benjamina 'Variegata', Dypsis lutescens, Dracaena marginata, Spathiphyllum spp., Hedera helix and Aglaonema commutatum 'Lady Valentine', which is similar to the results of a study on preference for indoor plants in 5 workplaces that respondents' preference for Anthurium andraeanum cv. was the highest (Ryou, 2015).

\section{Preference for the leaf colors of indoor foliage plants}

Subjects' preference for the leaf colors of indoor foliage plants was surveyed (Table 8), and there were statistically significant differences between subject's preferences for the leaf colors of indoor foliage plants $(\mathrm{F}=98.224, p=0.000)$. Their preference for green was the highest, followed by pattern, purple, red, yellow, orange and gray. These results are similar to those of a study that surveyed preference for the colors of indoor foliage plants by design category (Jang et al., 2016). In the study, the color that was preferred the most among 7 leaf colors of indoor foliage plants was green. In addition, since $80 \%$ of the data that humans obtain through their five senses are from visual elements expressed with colors in the surrounding environment, colors are very important for the delivery system of visual images (Moon, 2012). Therefore, green, the color of leaves, is very effective in improving humans' psychological stability and flexibility (Kim, 1997), which indicates that humans prefer the color green in nature. In addition, Ryou (2015) also reported that workers preferred the color green the most in their worksplaces, which supports the results of this study that green was preferred the most.

\section{Conclusions}

In this study, a questionnaire survey was conducted among 216 subjects in order to survey their emotional reactions to the visual elements of indoor foliage plants and their awareness of the importance of the plants. From the list of the "50 plants that clean the air" released by the National Aeronautics and Space Administration (NASA), 8 indoor foliage plants

Table 8. Preference for leaf color of indoor foliage plants

\begin{tabular}{|c|c|c|c|c|c|c|c|c|}
\hline & \multirow{2}{*}{ Color } & \multirow{2}{*}{$\mathrm{n}$} & \multirow{2}{*}{ M } & \multirow{2}{*}{ SD } & \multicolumn{4}{|c|}{ Scheffé's test $\alpha=0.05$} \\
\hline & & & & & 1 & 2 & 3 & 4 \\
\hline \multirow{9}{*}{ Preference } & Gray & 209 & 2.33 & 0.90 & $a^{z}$ & & & \\
\hline & Orange & 212 & 3.03 & 0.87 & & $\mathrm{~b}$ & & \\
\hline & Yellow & 211 & 3.10 & 0.90 & & $\mathrm{~b}$ & $\mathrm{c}$ & \\
\hline & Red & 210 & 3.19 & 1.01 & & $\mathrm{~b}$ & $\mathrm{c}$ & \\
\hline & Purple & 212 & 3.22 & 0.99 & & $\mathrm{~b}$ & $\mathrm{c}$ & \\
\hline & Pattern & 210 & 3.40 & 1.09 & & & $\mathrm{c}$ & \\
\hline & Green & 213 & 4.47 & 1.04 & & & & d \\
\hline & \multicolumn{2}{|c|}{ F-value } & \multicolumn{6}{|c|}{98.224} \\
\hline & \multicolumn{2}{|c|}{$p$-value } & \multicolumn{6}{|c|}{$0.000^{* * *}$} \\
\hline
\end{tabular}

Note. Likert 5-point scale was used for preference, where 1=dislike very much; $5=$ like very much.

${ }^{\mathrm{z}}$ Mean separation within columns by Scheffé's multiple range test, $5 \%$ level $(\mathrm{N}=216)$.

${ }^{* * *}$ Significant at $p<.001$. 
that can be easily grown and of which leaves have ornamental values were selected. The selected plants were planted in a white pot, and showed to subjects to survey their preference for foliage plants, their emotional reactions to the plants using the semantic differential (SD) method, their awareness of the importance of and loyalty towards the plants, and the correlation with their expectations on the therapeutic effects of the plants. In terms of the importance of indoor foliage plants, the importance level of environmental effects, aesthetic effects and emotional relaxation was high, and, in particular, those in their 40s or older were found to value environmental effects and emotional relaxation. The correlation between subjects' expectations on the therapeutic effects of indoor foliage plants and the questions on importance and loyalty was also reviewed, and emotional relaxation and the question "indoor foliage plants increase the natural healing power of the body" showed the highest positive correlation (over 0.4 ). In addition, the 5 questions of the expectations on therapeutic effects and the 5 questions of loyalty showed a statistically significant positive correlation. In particular, expectations on psychological stability improved by indoor foliage plants and expectations on working in a workplace that has a well-created indoor landscape showed a high correlation. There were statistically significant differences between emotional reactions to the images of 8 indoor foliage plants, and key emotional reactions include "comfortable", "likable", "calm", "bright" and "sharp". Respondents' preference for Anthurium andraeanum cv. was the highest, followed by Spathiphyllum spp., Ficus benjamina 'Variegata', Dypsis lutescens, Dracaena marginata, Spathiphyllum spp., Hedera helix and Aglaonema commutatum 'Lady Valentine'. Their preference for green, out of the 7 leaf colors of foliage plants, was the highest. The correlation between environmental factors, such as fine dust, stress and depression has been growing. In this regard, the results of this study that identified the effects of plants including stress relief, emotional relaxation and psychological stability support the usefulness of indoor foliage plants.

\section{References}

Choi, E.M. 2012. A study on expression types and characteristics of interior landscape designs as healing environment element-focusing on central waiting halls of large general hospitals in seoul-. Master's thesis, Chung-ang University, Seoul, Korea.

Dick, A.S. and K. Basu. 1994. Customer loyalty: Toward an integrated conceptual framework. J. Acad. Mark. Sci. 22(2):99-113.

Gremler, D.D. 1995. The effect of satisfaction, switching costs, and interpersonal bonds on service loyalty. Doctoral dissertation, Arizona State University, Arizona, USA.

Im, S.B. 2009. Theories in landscape analysis (Rev. ed.). Seoul, Korea: Seoul National University Press.

Jang, H.S. 2013. Influences of visual element of ornamental plants to emotion or electroencephalography of human. Doctoral dissertation, Korea University, Seoul, Korea.

Jang, H.S., E.H. Yoo, K.J. Kim, and H.H. Jung. 2015. Preference and image perception for color and shape in green interior. J. Korean Soc. People Plants Environ. 18(5):413-420. DOI:10.11628/ksppe.2015.18.5.413

Jang, H.S., G.M. Gim, K.J. Kim, and H.H. Jung. 2017. Psychological healing change of workers following after the experiencing indoor garden installation. J. Korean Soc. People Plants Environ. 20(4):373-383. DOI: 10.11628/ksppe.2017.20.4.373

Jang, H.S., K.J. Kim, E.H. Yoo, and H.H. Jung. 2016. Impact of indoor-garden in the public building of lounge to the psychological effect of resident. J. Korean Soc. People Plants Environ. 19(3):167-174. DOI: 10.11628/ksppe.2016.19.3.167

Jang, H.S., S.W. Kang, and C.H. Pak. 2011. Influences of psychological effect and importance perception from the visual image of the indoor plants upon the repurchasing intention. J. Korean Soc. People Plants Environ. 14(2):123-131.

Kaplan, R. 2001. The nature of the view from home: Psychological benefits. Environ. Behav. 33(4):507-542. DOI:10.1177/ 00139160121973115 
Kaplan, R. and S. Kaplan. 1989. The Experience of Nature: a Psychological Perspective. New York, NY: Cambridge University Press.

Kim, B.K. 1997. Study regarding visual preference anger analysis of an indoor landscape architecture plant. Doctoral dissertation, Kyunghee University, Suwon, Korea.

Kim, J.J. 2009. Visual preference about bench color in urban park. Master's thesis. Korea University, Seoul, Korea.

Kim, K.M. 2012. Study on the effects of forest healing according to types of recreational forests. Doctoral dissertation, Chungbuk National University, Cheongju, Korea.

Kim, S.Y. 2001. Effect of horticultural therapy on the functional rehabilitation in hemiplegic patients after stroke. Master's thesis, Konkuk University, Seoul, Korea.

Kwak, S.O. 2004. A study on the environmental marketing for interior scape within apartment. Doctoral dissertation, Sangmyung University, Cheonan, Korea.

Lee, G.G. 2006. Visual preference in green roof sites. J. Korean Inst. Landsc. Archit. 34(5):32-38.

Lee, H.I. 2010. Relationship between indoor plants in apartments and happiness index of citizens in Seoul. Master's thesis, Korea University, Seoul, Korea.

Lee, H.Y. 2008. Research methodology. Seoul, Korea: Cheogram Press.

Lee, J.Y. 2003. Effects of air transportation service delay on customer satisfaction, relationship quality, and customer loyalty. Doctoral dissertation, Gyeongju University, Gyeongju, Korea.

Lee, S.H. 2007a. A Comparison of the models for explaining the emotion-improving effects. Korean J. Health Psychol. 12(1):189-217.

Lee, S.H. 2007b. The effects of the index of greenness simulation based on restorative environment model upon emotion improvement. Korean J. Health Psychol. 12(2):439-465.

Lee, S.H. 2014. The realization of the spirit of positive psychology through natural environments: positive experience. Korean J. Psychol.: General 33(1):51-79.

Micro dust could be a high risk factor for suicide. 2018, February 22. ScienceTimes. Retrieved from http://www. sciencetimes.co.kr

Micro dust increases the suicided risk. 2018, February 22. YonhapNews. Retrieved from http://www.yonhapnews.co.kr

Ministry of Environment. 2016. Micro dust, What is it ? (11-1480000-001435-01) Retrieved from http://www.me.go.kr

Ministry of Health \& Welfare. 2018. The plan of government action for preventing suicide. Retrieved from http://www. mohw.go.kr

Moon, E.B. 2012. Traditional color of Korea. Seoul, Korea: Ahngraphics Press.

Osgood, C.E., G.J. Suci, and P.H. Tannenbaum. 1957. The measurement of meaning. Urbana, IL: University of Illinois Press.

Park, B.J. 2010. Experimental approach of therapeutic effect of forest recreation activities - focused on viewing and walking in forest environments-. Doctoral dissertation, Chungnam Nattional University, Daejeon, Korea.

Parsons, R., L.G. Tassinary, R.S. Ulrich, M.R. Hebl, and M. Grossman-Alexander. 1998. The view from the road: Implications for stress recovery and immunization. J. Environ. Psychol. 18:113-139.

Ryou, S.M. 2015. Analysis of the preference level of color and color scheme of indoor plants by workplace. Master's thesis, University of Seoul, Seoul, Korea.

Shin, S.S. 2015, April 1. Micro dust increases the suicide rate. JoongAng Ilbo. Retrieved from http://news.joins.com

Song, M.S. 2015. 'Indoor air purifying plants' introduced by Nasa. The Segye Times. Retrieved from http://www.segye.com

Ulrich, R.S. 1979. Visual Landscape and Psychological well-being. Landsc. Res. 4:17-23. DOI: 10.1080/01426397908705892

Ulrich, R.S. 1984. View through a window may influence recovery from surgery. Science 224(4647):420-21. DOI:10.1126/ science. 6143402 
Wilson, E.O. 2001. Natural matters. Am. J. Prev. Med. 20(3):241-242.

Yoo, M. 2007. Imagination of ornamental foliage plants according to the types of space for interior landscape design. Master's thesis, Seoul Women's University, Seoul, Korea.

Yoo, M. 2013. The impact of modulized interior landscape on office workers' psychological wellbeing. Doctoral dissertation, Seoul Women's University, Seoul, Korea.

Zeisel, J. 1981. Inquiry by design Monterey: Tools for Environment-Behavior Research. Monterey, CA: Brooks Cole Publishing Co. 